\title{
Converging Concerns: Feminist Bioethics, Development Theory, and Human Rights
}

ike feminist scholarship generally, feminist bioethics has been continually remaking itself as new issues emerge and conceptual shortcomings surface. This article has sprung from my growing realization of a limitation in feminist bioethics, which was prompted by the chance remark of a newcomer to the field, who, at a recent conference of the Feminist Bioethics Network, expressed her surprise that so few speakers had mentioned the human rights movement. Initially puzzled, I reflected on the network's mission statement, particularly its emphasis on the development of a more inclusive theory of bioethics encompassing the standpoints and experiences of women and other marginalized social groups, on the examination of the dominant bioethical discourse that privileges those already empowered, and on the creation of new methodologies and strategies that are responsive to the disparate conditions of women's lives across the globe. ${ }^{1}$

Given these long-term goals it now struck me that the range of feminist bioethics scholarship had been too constricted. My colleagues and I had yielded to the feminist trend to turn away from global thinking to emphasize local and contextual knowledges. ${ }^{2}$ Consequently, like much other feminist scholarship, our discourse had become more local as the world grew closer together (Benhabib 1995). In attempting to globalize feminist

I wish to express my gratitude to colleagues in the International Network on Feminist Approaches to Bioethics and the editors of this Signs issue who have contributed to my exploration of the problems I examine in this article.

${ }^{1}$ See the mission statement of the International Network on Feminist Approaches to Bioethics (FAB) at http://www.fabnet.org. The network currently has approximately 350 individual members in twenty-eight countries, publishes a semiannual newsletter, and organizes a biennial conference. Scholarship by its members has appeared in two anthologies (Donchin and Purdy 1999; Tong 2001). A third focusing on issues addressed in this article is scheduled to appear in 2004 .

${ }^{2}$ Notable exceptions include Florencia Luna (2001) and Jeanelle de Gruchy and Lauriel Baldwin-Ragavin (2001), who have already begun to explore specific interconnections between feminist bioethics and human rights.

[Signs: Journal of Women in Culture and Society 2003, vol. 29, no. 2]

(C) 2003 by The University of Chicago. All rights reserved. 0097-9740/2004/2902-0002\$10.00 
bioethics and advance health and well-being across diverse cultures and traditions, we had added a miscellany of diverse voices and given too little attention to major structural injustices that often override local boundaries. Subsequent conversations with colleagues in overlapping fields led me to two arenas of discourse and activism that address the intersection of global concerns and feminist bioethics: human rights and development theories. But critical exploration of the human rights movement would compel me to reconsider my own reservations about rights discourse. And forays into development theory would require rethinking my own, predominantly visceral, reactions to the dominant development paradigm. This article incorporates these reflections in the hope of developing a more coherent and integrated global framework for feminist bioethics. In order to strengthen connections among these overlapping arenas, I probe interconnections that might overcome the compartmentalization and bifurcations that impede collaboration among feminists who share a common commitment to global change. I hope to show how such linkages could enrich all three frameworks, thereby contributing to a truly global feminist program that links theory and practice in ways likely to enhance women's health and well-being across diverse cultures. Though my attention will be directed primarily to extending the feminist bioethics agenda, converging connections will, hopefully, encourage partnerships among feminists in all three fields.

In matters of health and well-being, all three groups already share commonalities. They recognize that health does not depend on behavioral choices alone but is the result of interlocking status determinants that affect people's capacities to realize tenable life goals. They also understand the need to shift the attention of providers and policy makers from an overemphasis on the delivery of health care services to a greater investment in preventive programs. And they are acutely aware of conditions that impair women's health and diminish their agency, particularly the health care needs of marginalized groups and those subject to abuse and neglect and the impact on health of abusive practices such as domestic violence, discrimination against female children, and demands for husbands' authorization of their wives' medical care. All also understand the impact of local, national, and international power hierarchies on the distribution of health care resources. Rather than merely deploring existing injustices, they call for programs of social change to rectify inequities, to empower marginalized people to define their own health care needs, and to configure local programs to meet those needs (Cook 1999; Holmes 1999; Nicholas 1999).

Building on these commonalities, I initially consider major critiques of 
rights-based theories, leading responses to them, and recent initiatives within the international bioethics community intended to reclaim human rights. Next, I shift to efforts within the human rights movement to advance global health and consider impediments generated by the dominant economic development paradigm. I then take up an alternative paradigm that seeks to forge a global ethic conjoining development and human rights theories. I evaluate an influential version of this approach and indicate respects in which it is flawed, noting particularly its failure to make adequate provisions for group relations that frame the context of individual lives. Finally, I propose an alternative framework for a global feminist bioethic that is more fully responsive to practices that would strengthen all people's capacities to enjoy healthy, productive lives.

\section{Rights speech: Reservations, rebuttals, and revisions}

Feminist resistance to a conceptual apparatus that stresses rights language has sprung from both sources external to feminism and tendencies within it. Prominent among the first group is the negative-positive rights polarity rooted in the liberal tradition. Feminist theorists often point out that a claim to a negative right obligating others to abstain from interference has little value without access to resources enabling its exercise. Take the right to noninterference: it is vacuous without authoritative implementation (consider access to abortion facilities or enforcement of prohibitions against rape). Even the right to self-determination requires considerable social cooperation. For it cannot be exercised even minimally without the mutual recognition of people's interdependence. Optimally, it requires mastery of appropriate cognitive and emotional skills, opportunities to shape one's identity in nonoppressive ways, and social support to achieve personal agency.

An overlapping concern is the tendency of rights-based theories to lapse into a rigid individualism that disregards the basic human needs of socially excluded groups. Developing this thread, feminists from a variety of traditions have spoken out about an overemphasis on individual rights, how it lends itself to an impoverished sense of personal and social values, and how it neglects other moral aims that are not expressible as matters of individual preference-relational ties, sexual equality, and a nurturing stable child-rearing environment. Some stress affinities between the appeal to rights and masculinist ideologies of personal control and domination and chide those who emphasize rights discourse for neglecting relational values tied to care and interpersonal connection. In a related vein others fault the conception of personal autonomy associated with rights discourse 
for its mentalistic assumptions that valorize a distinctively masculine ideal of autonomy that diminishes the importance of embodied particulars and relegates women to a natural sphere disjoined from human reason (Lovibond 1989, 10).

Diana Tietjens Meyers makes a related point, noting that appeals to rights are often made when there is a breakdown in loving and caring relationships-when people's interests are neglected. She sees the morality of rights primarily as a morality of self-defense used to protect people from assaults on their personal integrity. Invoking a right introduces a generalized perspective that captures one dimension of morality but does not tell us how to respect people individually (Meyers 1994, 155). I will revisit this perspective later within the context of relationships between human rights discourse and development theory.

A further factor in feminist distrust of broad appeals to rights stems from the early history of the international human rights movement, when women's concerns were relegated to the periphery. Despite the 1948 UN Charter's inclusion of a right to the highest attainable standard of health, linkages between health and human rights did not become a focal concern until the 1980s. The initial formulation addressed only civil and political rights. In response to pressures to formulate more concrete and potentially enforceable rights, in 1966 the UN General Assembly adopted a covenant incorporating social, cultural, and economic rights (known as secondgeneration rights). But even this extension did not expressly address equal protections for women and other marginalized groups.

Other sources of resistance to rights discourse stem from tendencies within feminist theory. Over the past two decades feminists have turned away from global thinking to emphasize local and contextual knowledges. Under Carol Gilligan's (1982) influence many have stressed patterns of reasoning allegedly characteristic of women - those based on caring, relationships, and responsibilities - and contrasted them to masculine modes of reasoning that privilege justice and rights. Though Gilligan did not regard either as superior, some of her followers, most notably Nel Noddings (1984), did. Noddings believed feminists could dispense with moral principles, including those that use the (masculine) language of justice and rights. Adequate moral guidance could be gleaned from individual cases where people exercise caring duties.

Despite feminist theoretical resistance to the use of rights language, rights talk has been integral to activist feminist strategies for decades. Within feminist bioethics, particularly, there has been broad support for women's right to reproductive services and the rights of patients to take control of their own medical decisions. However, feminist bioethicists have 
been reticent to extend rights language to a broader set of practices. Why so? This reticence can be explained, in part, by international criticism of U.S. bioethicists for their supposed obsession with rights language. What is seldom well understood by critics, however, is that appeals to rights are often rooted in specific features of the U.S. experience that arose at a time of major change in the expression of ethical principles and that marked a significant power shift from physician paternalism to patient autonomy. The articulation of these principles is historically linked to other rightsbased initiatives in the United States, particularly the civil rights movement and the struggles for women's rights in the 1960s and 1970s. Both movements brought to public awareness submerged voices and injustices inflicted on those lacking access to power.

Turning now to rebuttals to these critiques of rights talk, I will consider grounds for broader inclusion of rights language in feminist bioethics. One approach focuses on deficiencies in the theoretical turn exemplified by Noddings (1984), especially on its virtually exclusive emphasis on interpersonal relationships and its disregard for the political dimensions of social connection. Martha Minow addresses the difficulty of holding together a vision encompassing both the personal and political. Responding to injustices suffered by marginalized groups, she has framed what she calls "the dilemma of difference": ignoring group differences undermines efforts to mobilize opposition to group discrimination, but emphasizing differences risks entrenching the dominant group's stereotypes about the discriminated $(1990,20){ }^{3}$ She attributes the dilemma to social institutions that establish only one norm, thereby ignoring the perspectives of those who fall outside that norm (94-95). An exclusively case-oriented perspective, such as Noddings advocates, would obscure these effects of social institutions.

Others have pointed out that rights talk cannot be expunged from a language that preserves concepts bound up with duty and obligation. ${ }^{4}$ While resisting propensities to totalize rights language, they emphasize its central functions. "For the historically disempowered," Patricia Williams remarks, "the conferring of rights is symbolic of all the denied aspects of their humanity" (1991, 152). Williams stresses the need to assess the value of rights not only from the privileged position of those who have always had them but also from the position of those to whom they have been denied. For U.S. blacks, particularly, "the attainment of rights signifies the respectful behavior, the collective responsibility, properly owed

\footnotetext{
${ }^{3}$ Others have constructed variants of this dilemma. See, e.g., O'Neill 1993, 307.

${ }^{4}$ For more on this point see Minow 1990 and Tong 2004.
} 
by a society to one of its own" (1991, 163). Rights talk, when uttered by people with the protected standing of bearers of rights, is a socially empowered form of speech. Lacking it, Margaret Walker notes, people may voice preferences or complaints but cannot articulate demands that others are required to meet $(2003,175)$.

Concurrently, the human rights movement has extended its scope beyond the two categories of rights formerly identified and has turned to the explicit recognition of women's rights, the rights of peoples (as distinct from states), and the right to development. The Convention on the Elimination of All Forms of Discrimination against Women (CEDAW) stresses basic education, career, vocational, health, and family planning information. It also incorporates mechanisms for monitoring injustices, including inequitable access to health care services (British Medical Association 2001, 333). Signatory governments, if found deficient, are obligated to respond. Walker $(2003,171-72)$ notes that many provisions of CEDAW grew out of the women's movements and come much closer than any prior document to reflecting the lives of women who have been systematically silenced and to addressing those oppressions that are based on group membership. Michael Ignatieff, reviewing the past five decades of the human rights movement (2001c, 169), acclaims its transformed agenda, which emphasizes social protections against threats to human well-being, the empowerment of victims, and the validation of their entitlements to freedom.

Feminist bioethicists could considerably advance the project of globalizing bioethics by reassessing reservations about the adoption of a more inclusive rights discourse and by giving greater heed to the aims of CEDAW. Available evidence shows a high correlation between gender oppression and preventable illnesses, particularly in countries with a strong preference for boy children (Drèze and Sen 1989). However, to address these issues adequately we need a conceptual apparatus that transcends dichotomies between developed and less-developed countries, incorporates a compatible development ethic, and integrates relevant features of the global human rights movement into feminist discourse. Medical groups in a few countries outside North America have already broken ground at a practical level.

Some medical organizations are coming to realize that physicians play a significant role in both the concealment and exposure of human rights violations. Since physicians are often the first beyond law enforcement officers to see evidence of the systematic violation of human rights, they have a heightened responsibility to protect the rights of those in their charge, and they deserve protection for reporting abuses. The Handbook 
published by the British Medical Association (2001) offers a rich source for exploring the extensive overlap and interconnections between the conceptual frameworks of bioethics and human rights and their practical applications. Most important, it facilitates understanding of the ways in which bioethics and human rights provide complementary approaches to improving the health of vulnerable populations, particularly within poorer countries; advancing their well-being; pressing for equitable access to treatment; protecting women's health and reproductive rights; developing nondiscriminatory HIV/AIDS policies; and encouraging practitioners to act as agents and advocates for social justice.

Issues overlapping bioethics and human rights include the health care of vulnerable groups, dilemmas about how to respect cultural diversity without jeopardizing the rights of individuals and groups, securing meaningful informed consent to research (particularly where drug companies in advanced industrialized countries exploit people in less-developed ones to research drugs for the market), discrimination in the delivery of health care services, and connections between such underlying determinants of health as nutrition and sanitation. Poor nutrition associated with poverty aggravates the health problems of pregnant and lactating women and increases their vulnerability to poverty-related diseases. ${ }^{5}$ Food contamination, infant dehydration, and other life-threatening conditions are responsible for many infant and child deaths (Mata 1988). Rebecca Cook observes that "promotion of women's health depends on the interaction of most, if not all, human rights" $(1999,260)$. She specifically mentions the protection of women's employment and equal pay for work of equal value, education, information, political participation, influence, and democratic power within legislatures.

To recapitulate, though feminist reservations about rights language are often directed more to misleading theoretical expositions of rights than to activist strategies, they have practical consequences too. Theories that make inadequate provision for rights risk obstructing the advancement of subordinated groups. But moral theories that give centrality to individual rights can provide only a partial moral vision. For rights-based moral thought alone can tell us nothing about what should be done in the absence of claimant procedures. What is needed is a moral framework that encompasses rights claims within a broad range of moral norms, a framework that is fully responsive to conditions that shape human health and

${ }^{5}$ For a fuller discussion of associations between health and poverty, see Jaggar 2003, 198-203, and the sources cited there. 
well-being across the globe. However, efforts to shape such a framework need to be responsive to the resistance to a global bioethic that encompasses human rights. I turn now to the principal sites of resistance.

\section{Global health and the dominant development paradigm}

Of course, criticisms of rights language extend well beyond feminist contexts to moral thought in general as well as to central claims of the human rights movement. Despite successive reformulations of human rights, some bioethicists still think human rights language is too closely tied to EuroAmerican bioethics to contribute meaningfully to a global bioethic. According to Ruth Macklin, opposition to human rights is widespread among Chinese scholars $(1999,228-33)$. Other Asian scholars advocate a very particularized global approach that counters claims to universal human rights. Defenders of this view assert two related claims. First, in many countries in East and Southeast Asia, people have no theoretical background for the concept of human rights. Second, these people seek primarily to overcome starvation and poverty by increasing national wealth and mutual aid (Sakamoto 1999). Arleen Salles and her collaborators report similar arguments rejecting human rights claims among some Latin American scholars (2002).

Several considerations need to be taken into account to evaluate the responses. Regarding the second objection, it is often not commodity scarcity that causes famine, injustice, and other factors that contribute to ill health but socially produced deprivations such as the lack of legal and other entitlements to food and income (Sen 1990). Among these missing entitlements is appropriate maternal education to enable mothers to avoid food contamination, infant dehydration, and other life-threatening conditions that are responsible for so many infant and child deaths (Freedman 1999). I will turn to a more detailed discussion of this issue in the next section, where I argue that bolstering economic assistance to poorer countries is not incompatible with human rights advocacy. Denial of a human rights tradition in Asia is also highly questionable. Amartya Sen has unearthed evidence dating human rights advocacy within the Indian tradition to the twelfth century (2000). And Salles points out that the independence movements of several Latin American countries based their demands on claims to natural rights, the antecedent of human rights (2002).

Though the modern formulation is undoubtedly Western in origin, as Sen's evidence illustrates, moral discourse that emphasizes rights is a descendant of older concerns about obligation and justice, virtue and happiness, that have been ubiquitous in ethical discussion since antiquity. Not 
until the seventeenth century, though, were the legal dimensions of this discourse extended to the situation of women and other disenfranchised groups. The agendas of the social movements that culminated in the French and American revolutions provided the context for a conceptual shift to human rights discourse as well as a family of interrelated concepts that have been central to moral discourse ever since. Though these movements fell far short of their ideals, their stress on the universality of rights laid the groundwork for contemporary rights claims. The struggles for voting rights, for full participation in the workforce, and for equal opportunity for minority populations are all descendants of these movements and are grounded in a conception of a common humanity based on shared human needs.

Seen in this light the unqualified rejection of human rights discourse that marks some non-Western approaches to bioethics seems directed more to those who already have control over the basic conditions of their lives than to those living on the margins who lack the economic security and reliable social support that the more privileged take for granted. However, as I noted previously, the value of rights needs to be assessed not only from the privileged position of those who already have them but also from the position of those to whom they have been denied. Once human rights are understood as the moral rights of all people in all situations, the central issue is transformed from whether human rights claims should be included within moral discourse to how to identify and characterize them. ${ }^{6}$

The application of this criterion provides a yardstick for evaluating models of economic development directed to improving living conditions in developing economies. In the next section, I will examine in detail the human capabilities model advanced by Sen and Martha Nussbaum, but first I will take up the model that has dominated international assistance programs in developing economies. Based on a quasi-utilitarian model of preferences that prioritizes economic values, it takes a country's gross domestic product to be the measure of the quality of life of its inhabitants and assumes that people's expressed preferences represent their actual needs and wants. Institutions that direct globalization support this paradigm. Control of these institutions intensifies the West's economic dominance through programs of national-multilateral "security" that exacerbate the marginalization of populations that cannot contribute significantly to wealth expansion. Alison Jaggar (2003) documents how economic globalization contributes to

${ }^{6}$ This is the characterization of human rights preferred by both Williams (1991) and Macklin (1999), esp. 225-28. 
growing disparities in health outcomes for women worldwide. She, among others, has taken the International Monetary Fund to task for championing market supremacy and insisting on repayment of wealthy creditors even when reimbursement impoverishes the domestic economy of the debtor nations and intensifies their poverty, because forcing debtor countries to repay loans regardless of the condition of their economy severely diminishes the resources available to support the health and well-being of their people. For example, the intellectual property rules that require poor nations to honor drug patents will result in a transfer of $\$ 40$ billion a year from poor countries to corporations in the developed world (Rosenberg 2002). Other stratagems employed by Western economic interests include co-optation of rights language to distort and threaten alliances between Western women and those in developing economies. Some feminists fault these interests for using the cloak of reproductive rights to hijack the agenda of population control programs by manipulating women's reproductive capacity to achieve the demographic goals set by dominant elites (Freedman 1999, 234).

However, in some of these countries feminists have begun to seize the initiative, restoring the vitality of rights discourse and opposing the treatment of women as "targets" of contraceptive programs. Women from Asia, Africa, and Latin America have played leading roles in defining the terms and setting the direction of women's human rights movements (as well as reproductive health and rights movements) both in their own countries and at the international level. Several groups are now seeking to counteract programs that would narrow the human rights agenda to the advantage of the West. In a recent address to the World Bank, Mary Robinson, the United Nations high commissioner for human rights, summarized recent efforts within the United Nations system to channel economic growth resulting from globalization to eradicate poverty, inequality, and deprivation. She called for "ethical globalization" that would make the full complement of rights articulated in the international human rights standards available to all (2001).

\section{Human rights and capabilities models of human development}

Economist Amartya Sen, joined by a number of development scholars, has questioned the economic development model on two interrelated grounds. First, as I pointed out earlier, famine, injustice, and other factors that contribute to ill health are due primarily not to commodity scarcity so much as to socially produced deprivations, including lack of entitlements to food and income. Second, the desires and preferences expressed 
by people who live under oppressive conditions may not provide an adequate guide to their actual needs for either survival or flourishing. Sen (1985) cites health surveys in India that document disparities between women's self-reports about their health and their actual health status. The weight of patriarchal social structures and the ancestral history of women's subjection may distort their consciousness, so they internalize prevailing social norms and fail to recognize their own actual needs. In such instances, Sen insists, their preferences are deformed.

Based on these criticisms Sen has developed a comprehensive economic strategy for encompassing development goals within a more inclusive theoretical framework that takes into account aspects of all three generations of human rights ratified by UN member states: civil and political rights; social, cultural, and economic rights; and rights that protect marginalized social groups. The approach to human development that he has pioneered is known as the capabilities approach because, instead of taking gross domestic product as the measure of wealth, it weighs people's capability to lead lives of their own choosing.

In 1986, Nussbaum and others joined Sen in a collaborative UNsponsored project to incorporate interdisciplinary perspectives into development projects. In a succession of works $(1992,1998,1999,2000)$, Nussbaum has sought to provide philosophical grounding for a specific version of the capabilities approach. She distinguishes her model from Sen's by its explicit disavowal of relativism, its conception of human functioning derived from Marx and Aristotle, and its enumeration of specific central capabilities. ${ }^{7}$ Following John Rawls's thought experiment (1971), she imagines a hypothetical group of people deprived of all knowledge about their social position, natural assets, and specific conception of the good life. They assemble to specify fair terms of cooperation for regulating the basic structures of society. She reasons that they would aim at equality of capability rather than equality of resources, since the latter would be more likely to lead to unequal outcomes that could affect them adversely; some people-for example, disabled people or those who need more food because they perform hard physical labor-might need more resources than others to achieve a comparable quality of life (Nussbaum 1992). She then enumerates ten functional capabilities, including bodily health, adequate nourishment, and shelter, that people require to freely choose lives they personally value $(2000,78-80) .{ }^{8}$ Understood in this way, the ca-

\footnotetext{
${ }^{7}$ For a more detailed discussion of her differences with Sen, see Nussbaum 2000, 11-15.

${ }^{8}$ Nussbaum has continually revised her formulation of the functional capabilities. I summarize only her most recent version.
} 
pabilities approach has profound implications for development strategies aimed at implementing health-related rights.

Nussbaum, like an increasing number of other scholars and development organizations (e.g., World Bank 2001), has recently turned her attention to the broad economic and social implications of gender discrimination in developing and transitional countries. Nussbaum's concern, however, is also directed to the influence of patriarchal religious communities on women's ability to enjoy healthy, satisfying lives. A recent remark by Ignatieff, reputedly an ardent supporter of human rights, aptly illustrates the kind of insensitivity to gender hierarchies that creeps into Western scholars' attempts to avoid criticism of other cultures' religious practices. In the course of a discussion urging equal political representation of the interests of the powerless, he asserts: "If, for example, religious groups determine that women should occupy a subordinate place within the rituals of the group, and this place is accepted by the women in question, there is no warrant to intervene on the grounds that human rights considerations of equality have been violated" $(200 \mathrm{lb}, 19)$.

Unlike Ignatieff, Nussbaum is not averse to taking on the naturalizing hierarchies of power and privilege that persist in many religious communities and contribute to the continuing impoverishment of women. She also recognizes connections between these hierarchies and privatized family structures that exploit women's labor only as a means to collective family well-being. Her sensitivity to these issues leads her to focus on the embodied individual as the basic unit for political thought. She develops a rationale for distributing resources in ways that attend to the well-being of all individuals whatever their capabilities and wherever they fall in the life span. This approach has the advantage of addressing specific development goals within a more encompassing global context than the leading development paradigms. In this respect her model, like Sen's, is compatible with features of third-generation human rights that attempt to specify human rights more concretely than earlier conceptualizations.

Nussbaum recognizes the dominance of rights language in the international development world and acknowledges a very close relationship between capabilities and rights, but she prefers to take capabilities as her starting point $(2000,97-101)$. She believes that rights language often obscures difficult questions and can create the illusion of agreement where there is actually deep philosophical disagreement. Examples she cites include differences about the basis of rights claims, relationships between rights and duties, whether rights belong to individuals or groups, and what the rights holder has a right to. She prefers to think of both firstgeneration (liberty) rights and second-generation (welfare) rights as com- 
bined capabilities that provide a benchmark for thinking about what it means to secure someone's right. However, she does not wish to do away with rights language altogether. She enumerates several important roles that it plays in public discourse: reminding those in power that people have certain justified claims whether or not anyone has done anything about them, emphasizing people's choice and autonomy where rights are guaranteed by the state, and preserving a sense of a terrain of agreement. Her comments suggest the possibility of interweaving both the capabilities model of development ethics and rights discourse within a common pluralistic framework. Before addressing this point, however, I would like to consider some limitations in her theoretical framework that cry out for more comprehensive strategies. I will focus first on the most serious-a disregard of individuals' connection to a nexus of group relationships that shape their identities and regulate their social positioning. Then I will briefly mention several others.

\section{Integrating group identifications into a development paradigm}

Nussbaum's account of capabilities recognizes only two levels of identification: the universal and the individual. Within her scheme the individual is the basic unit for political thought. She understands the central capabilities I have enumerated as universal norms of human functioning. To protect the universality of her account and save it from charges of relativism, she deliberately excludes social groups from her structural framework. Feminist accounts, she is convinced, have a tendency to slide into relativism by employing "collectivist means to individual ends" (1999, 67). She apparently believes that the only way to avoid this snare is to base moral claims on universal human capabilities rather than social endowments or relations $(1999,72)$. To her conviction that individuals have an essential core of moral personhood, she recognizes only one alternative, "communitarian anti-essentialism."

But feminists who call her formulation into question are not, by and large, either Marxist "collectivists" or liberals (in the classical sense defined by Jaggar [1983]). They tend to resist claims founded on purportedly universal human qualities because such appeals have historically been used

\footnotetext{
${ }^{9}$ It is noteworthy that in her subsequent book only a year later Nussbaum disclaims commitment to any particular view of the person or human nature $(2000,76)$. It is not easy to reconcile the two claims even if she is taken to mean that though the capabilities she enumerates are derived from human nature, the more comprehensive theory of justice she avows is not.
} 
to shield oppressive political practices from scrutiny and to justify patterns of discrimination that exclude women from educational and social opportunities. Feminists who wish to circumvent cultural relativism commonly employ other strategies that bypass essentialist commitments. Though Nussbaum's version of essentialism may be comparatively benign, the case for a capabilities approach might be articulated in other ways that avoid appeals to both human essences and individual-collective dichotomies. ${ }^{10}$ The case for universal human rights is often launched on grounds that presuppose no comprehensive theory of human capacities. Ignatieff builds such a case on human history, taking into account memory of the horrors unleashed by the Nazis (2001a, 80-81). In an extended response to ethical relativism, Macklin (1999) distinguishes between values specific to cultural groups and a class of actions falling under the umbrella of human rights that pertain to health, well-being, and survival universally. Macklin declines to delve into deep theoretical questions about the sources of the latter group, preferring to rely on agreement within the international community. Feminist scholars have utilized several overlapping strategies to counter moral relativism. Susan Sherwin (1992) mounts a persuasive case for the universal condemnation of all forms of oppression, and Seyla Benhabib (1999) defends a modified version of Kantian autonomy that emphasizes the ability to adopt the standpoint of the other.

Such approaches can accommodate social groups in a nonindividualistic way. Iris Marion Young (1990) has built a cogent case for conceiving of groups as not mere aggregates or associations of individuals but as representing a distinctive kind of collectivity whose members have a special affinity with one another based on their similar experience or way of life. They need not have a complete identity of interests but may hold only certain interests in common around which their group identity is constituted and maintained. Insofar as they hold group rights, these would be limited to their common interests. Individuals would be free to remain in the group, leave the group, or join another. ${ }^{11}$ Hence, the advantages that Nussbaum associates with individualism (women's freedom from domination by oppressive families or political regimes) might be achieved without forgoing the affirmative values of group affiliation. Examples of

\footnotetext{
${ }^{10}$ In response to Nussbaum's position on this point, see Flax (2001), who takes Nussbaum to task for conflating human capabilities with human nature, thereby relegating power relations to the background.

${ }^{11} \mathrm{I}$ am not persuaded that this is always possible. In an article extrapolating from quandaries in genetic decision making (Donchin 2000), I argue that family members may break off contact with kin, but terminating the residue of psychological and biological connection may be far more difficult.
} 
groups that meet these criteria vary widely and include the kinds of traditional groups recognized in the third generation of human rights enumerated by the United Nations as well as resistance groups including the Madres de Plaza de Mayo in Argentina and the women's networks in Nigeria that I discuss below. In this manner a development theory could accommodate groups as collectivities without jeopardizing the basic rights of individuals or privileging protections afforded to one group over those of others.

Even liberal scholars such as Rawls (1999) view human rights within the context of associations that are necessary if individuals are to enter into schemes of social cooperation. But Nussbaum's theory bypasses even this intermediate level of affiliation. Her omission is surprising, considering that the World Health Organization's definition of health and subsequent documents based on it all extend the conception of health promotion to groups as well as individuals (Mann et al. 1999, 8). Moreover, many rights proclaimed by the United Nations, including the right to development, entitle people to goods that are only accessible through participation in a particular community or group. Other rights specific to groups include nationality, civil association, political participation, union affiliation, and cultural life as a group member. David Ingram points out that the freedom of religion, freedom to work, and freedom from insecurity and ignorance are also rights that individuals are unlikely to exercise apart from group participation $(2000,242-43)$. Like some feminist scholars cited above, he holds that all rights are inherently relational since they presuppose social guarantees and other positive enabling conditions (247).

Nussbaum's rejection of collective means is particularly puzzling in light of her remarks about people's identification with community values that they have not deliberately chosen and her passing references to groups of powerful people $(1999,70)$. Moreover, development scholar Martha Chen (1995) associates Nussbaum's approach with her own work among indigenous private development agencies in Bangladesh that have broken with local tradition, which forbids women to work outside the home. These agencies enter into participatory dialogue with local communities in order to promote the gainful employment of those who have been denied the economic security that tradition is supposed to offer. Chen explicitly identifies these strategies with Nussbaum's approach (Chen 1995, 40), but there is no place to fit such groups into Nussbaum's framework.

The universal-individual polarities imbedded in Nussbaum's theory obscure both the patterns of group discrimination that impinge on individuals' abilities to fulfill their capabilities and the seeds of empowerment that group affiliation can provide. Feminist accounts depart conspicuously 
from Nussbaum's perspective in their recognition that individuality is inevitably situated within particular configurations of power relations and social connections that provide nurturing, care, and identity (Donchin 2000). People are dependent on their social milieu not only to satisfy their most basic physical needs but also to guarantee their self-affirmation and dignity (Freedman 1999, 237). Failure to take systematic account of the social, political, and relational matrices on which identity is produced and maintained seriously weakens any program aimed at implementing a conception of justice that dislodges traditional gender and class hierarchies. Struggles to alter conditions under which women live on any part of the globe are bound to misfire if they disregard local group arrangements, for local people are uniquely situated to anticipate dislocations in adjacent areas of life resulting from social change and to mobilize responses to them. And they can draw on their own indigenous networks to resist dominant norms. Without the collaboration provided by cohesive groups, marginalized and impoverished individuals are unlikely to gain the widespread social support and resources needed to develop their capabilities and become agents of personal and social change.

The kinds of problems that arise when local perspectives are disregarded have been dealt with at length in the controversy that erupted over the film Warrior Marks (1993), which was produced by Alice Walker, and her related novel Possessing the Secret of Joy (1993). This debate aptly illustrates problems that arise when Western activists bypass indigenous local groups. Walker's campaign to rally support condemning the practices of African communities that participate in ritual cutting of young girls' genitals was much criticized by African women as still another manifestation of Western imperialism. Critics charged that her film portrays the African continent as a monolith and uses female genital mutilation as a gauge by which to measure moral distance between the West and the rest of humanity.

These critics insisted that the struggle to transform such traditional practices is better left to those who are sensitive to the social conditions that perpetuate them and who can foster change in ways less likely to intensify the oppression of these women. A New York Times op-ed piece by Seble Dawit and Salem Mekuria (1993, A27) put it this way: "Genital mutilation does not exist in a vacuum but as part of a social fabric, stemming from the power imbalances in relations between the sexes, from the levels of education and the low economic and social status of most women. All eradication efforts must begin and proceed from these basic premises." They urge the formation of partnerships with African women; such partnerships would use the power and resources of the West to create space for these women to speak out and to speak with us. 
Through such dialogue policies might be developed to change the ways that such women are socially perceived, both by themselves and by others (Valdés 1995, 428). Crucial to such an undertaking would be encouraging the capacity to reflect critically on the patriarchal status quo ( $\mathrm{Li} \mathrm{1995,}$ 409). Of course, critical reflection would be pointless without the power to implement alternative courses of action. ${ }^{12}$ From this vantage point an even stronger case can be made for indigenous programs aimed at advancing gender equality by expanding opportunities at both individual and group levels, empowering the development of critical reflection skills, and fostering local alliances to create alternative group practices within communities. $^{13}$

Several further considerations also favor a development theory that incorporates an intermediate level of social affiliation. First, to achieve a more just redistribution of resources it is necessary to demonstrate inequalities within the prevailing distribution. Unless individuals are envisaged within a sociopolitical context, disparities among resources available to them are likely to appear as mere aberrations, not the result of systemic neglect. Only by noting group imbalances is it possible for policy analysts to realize the full implications of maldistribution and to bring to light the assumptions that have brought it about. Moreover, as Uma Narayan points out $(1997,11)$, without collaborative reflection among similarly situated women, individuals are unlikely to recognize that their own deprivations are part of a pattern of cultural norms that reflect their position within the social structure. Narayan speaks of her own mother in India, who frequently complained about the oppressive conditions that bound her but was unable to see that her oppression did not stem primarily from the behavior of particular individuals, such as the mother-in-law who maltreated her, but from the social structure that assigned mothers-in-law to positions of such authority.

Second, traditional relationships and dislocations within a local culture can often be mobilized to tap human potential. Despite resistance from entrenched bureaucrats, indigenous groups have built partnerships for change. In many areas of the globe the traditional work done by women and the power these responsibilities confer on them can serve as powerful catalysts for social change and empowerment. Narayan, like many feminists working in development studies, recognizes that cultures are seldom monolithic but incorporate within themselves a diversity of norms and values that may not be mutually compatible. Salles, generalizing from her own

12 This position has been developed particularly forcefully by Benhabib (1999).

${ }^{13}$ On this point see Sherwin's cogent discussion (1992, 61-62). 
Latin American experience, points out that "the cultural identity of a community is always in a state of evolution or transformation" (Salles $2002,18)$. I referred above to Chen who stresses the evolving character of rural South Asian cultures as they respond to internal (often local) tensions and instabilities that compel women to end their traditional seclusion and seek employment outside the home. Margarita Valdés (1995) makes an analogous point from the perspective of Mexican culture. She extends to developing economies Susan Moller Okin's (1995) observation about developed countries: employment makes women less dependent on men and improves their status within the family, thereby strengthening their bargaining position in relation to men. Furthermore, Valdés points out, having a job breaks the social isolation of women who had been bound to the domestic sphere, thereby enabling them to function in different social spheres and take action to improve their living conditions. She notes that in the large Mexican cities many poor women workers have organized themselves to demand urban reforms and contest the division of work according to gender $(1995,430)$. Examples such as these show that indigenous women's groups can often intervene at the intersection of local tradition and social instability to direct social change along paths that only they can identify as most likely to improve their living conditions.

Works by Obioma Nnaemeka (1996, 1997) and Nkiru Nzegwu (1995) illustrate the numerous practices of cooperative reform and resistance practiced by African women, particularly among grassroots networks of affiliated women's groups that constitute the backbone of local development. Nnaemeka shows how the structures of indigenous culture guarantee and maintain the existence of these networks, and she points out how some of the most successful development programs in these countries are "conceived, designed and executed by the national or local government organizations" (1996, 274).

Nzegwu (1995) chronicles the economic and social power that women held in Igbo culture prior to colonial rule. Indigenous cultural traditions valued female assertiveness and collectivity. Women utilized their networking skills to mobilize across cultural, religious, and economic boundaries, effectively resisting male encroachment on their independence. But after colonial powers imposed their own scheme of gender-specific values on Igbo society, women were reclassified as dependents, a status that precipitated the 1929 Women's War disclaiming their invisibility. Nzegwu's account vividly portrays the effects of the sexist system imported by the British colonizers and shows how co-optation of African men into Western gender stereotyping damaged Nigerian political culture. Today development projects are still targeted at men, and wide disparities in the incomes of men 
and women persist. Nzegwu urges developers to consider the diverse character traits of groups of women and to be responsive to alternative models of experience and organizational skills. But it is not only developers who have hindered Nigerian development. Granddaughters of the women who fought the Women's War have taken on a wealthy multinational oil company that has drained their country's natural resources and contributed nothing to local development. They are now demanding that this company employ more local people, invest in infrastructure projects, and assist villagers to supply food to the company's employees. Their strategies draw on the tradition of market trading by women and modes of protest deeply rooted in their indigenous culture (Peel 2002).

By such means African women have been challenging both multinational companies and technically oriented development projects that have irresponsibly imposed changes depriving local economies of resources needed to meet subsistence needs. They question the effectiveness of largescale centralized programs and recommend that development assistance be adapted to local institutional structures and cultural environments. And they insist that companies that drain local resources share their profits with the local economy. They draw on an established tradition of group cohesiveness concentrated in the intermediary political and cultural spaces of prevailing networks and historical relationships stretching between the family and the state. ${ }^{14}$

Nussbaum's interpretation of the capabilities model is largely silent about the tendency of multinational corporations to exploit the resources of developing economies. Sensitivity to varying cultural contexts and crosscultural influences would greatly enhance the case for the universality of the capabilities approach to human development. Recognition of universal human capabilities has major implications for the responsibilities of wealthier countries both to less-developed ones and to pockets of poverty, health care disparities, and gender inequalities in their own economies. Okin notes that when comparisons are made between the living conditions of poor women in developed and developing countries, disparities between economies diminish considerably. She points out that though the severity of their poverty may be greater in poorer countries, patterns of discrimination in developed countries are very similar, particularly within family units (Okin 1995, 284). Moreover, though imbalances in access to health care among economic groups and disparities in maternal-infant morbidity and mortality may not be as severe in richer countries, their injustice is

${ }^{14}$ For the views of other scholars seeking to counter the dominant development paradigm, see contributors to Munck and O'Hearn 1999. 
all the more striking since the resources needed to rectify such imbalances are readily available. An analogous point can be made about violence against women. Cass Sunstein cites data showing that women are the victims of both public and private violence in similar proportions in both developed and developing countries $(1995,357)$.

One final point about Nussbaum's formulation: her insistence on locating human rights within liberal theory risks undermining pragmatic aspects of the human rights movement and getting in the way of efforts by international bodies to forge consensus around practical goals. Within the bioethics community it has already been shown that it is far easier to reach common ground at the level of practice (on the basis of what Sunstein [2001, 49-66] calls "incompletely theorized agreements") than moral principle. Anthony Appiah points out that unlike the U.S. Constitution, the international human rights framework has an important advantage in that it does not proceed by deriving human rights from metaphysical first principles (2001, 104). This was a deliberate strategy on the part of those who drafted the framework, for they were aiming to achieve universal assent. Even among so-called liberal countries there is widespread disagreement about how to prioritize theoretical principles. Some question even the desirability of formulating principle-based frameworks for medical decision making. The Scandinavian countries, for instance, tend to emphasize social welfare and patient entitlements, while several others (most notably the United States) emphasize individual rights (Dickenson 1999). The consensus achieved in such agreements as the Council of Europe, the Convention on Human Rights and Biomedicine (1997), the Bioethics Declaration approved by the World Conference of Bioethics in Gijón (2000), and the UNESCO Document on the Human Genome (1997) was possible only by focusing on concrete goals and bypassing any single overarching grand theory.

\section{Toward an alternative framework}

Considering the range of disagreement, a multipronged pluralistic approach seems far more likely to contribute to alleviating injustices than a unified theoretical design. To be effective in countering global economic and political interests that flout human rights, we must move beyond even the empathetic identification with the situation of the deprived that feminist theorists have endorsed. Feminists need to forge links with likeminded groups to thwart power elites intent on bypassing the rights of oppressed people. Narayan's mother failed to understand the forces that victimized her, so she misidentified the source of her oppression. Similarly, many women who submit to genital cutting see themselves as having no 
effective options within the social context that frames their lives. It is vital that as people are awakened to their deprivations they be empowered to develop viable alternative institutions and practices.

There is need, then, to work cooperatively at both theoretical and practical levels to challenge the dominant economic development paradigm and to foster a more nuanced and fully integrated conceptual apparatus that combines human rights discourse with a flexibly constructed capabilities model that is responsive to changing conditions in local cultures. In some cultural contexts, such as African communities where a tradition of local women's groups persists, local knowledges and affiliations should be reinvigorated. In others (e.g., Mexico) where traditional male privileges have blocked the formation of women's alliances, new relational networks need to be encouraged to advance women's interests. To be of practical use, this alternative paradigm should recognize both traditional and innovative local alliances, thereby contributing to structures that enhance women's agency and well-being both individually and collectively. As has been shown with HIV/AIDS medical therapy and prevention work in the Asia-Pacific region, individual empowerment is inextricably interwoven with the well-being of communities. Only if human rights are protected at the local level can individuals be empowered to make the fully informed choices that create a climate for dealing effectively with disease prevention and intertwined conditions that perpetuate discrimination and block reconstruction of the cultural fabric of oncemarginalized communities (Bagasao 1998).

Vital, too, is support for the expanded definition of health advocated by the human rights supporters and alliances with women working in the movement to strengthen overlapping agendas. With a few notable exceptions, infrastructure development has a far greater impact on health than specific medical interventions. And the net needs to be cast still wider. For the promotion of women's health in particular depends on the interaction of many human rights-including rights to employment, education, information, political participation, influence, and democratic power within legislatures (Shinn 1999). To call attention to the multiplicity of factors affecting health, we need to mobilize across divides of race and ethnicity to advance debate and build coalitions to pressure for the implementation of the full complement of human rights.

Feminist bioethicists can contribute to this program by integrating into our perspectives relevant features of both human rights discourse and a capabilities approach to development. We need to restructure our framework to supplant the dominant individualistic bias with the recognition that individual identity is constituted and maintained through relational 
networks. To this end, I propose adopting and implementing the strategy Sherwin (2001) has put forward for the future development of bioethics. Instead of aiming at any single grand theory, we should reconceive moral theories as multiple perspectives that provide partial and overlapping resources to address difficult moral issues. Within such a reconception, feminist bioethics, development theory, and human rights discourse would offer overlapping and interlocking "lenses" to illumine dimensions of moral problems obscured by accounts that are structured by a single overarching theoretical matrix.

Such a reworked moral framework offers the best promise for revealing structural injustices that are masked by prevailing approaches; reshaping social conditions to promote the autonomy, health, and well-being of subjugated peoples across diverse cultures and traditions; and removing barriers that impede women's full participation in both local and global networks. Feminists working in both bioethics and development theory can play an important role in this enterprise by linking their conceptual frameworks in a manner that preserves the universal dimension of human rights without neglecting the distinctive contributions local groups can make to overcoming oppressive conditions. On a practical level, alliances should also be forged with human rights groups that are challenging dominant development paradigms, which advance the interests of elites at the expense of marginalized individuals and groups. Such integration would benefit both development theory and feminist bioethics. Hopefully, by this means feminists can forge a truly global feminist framework.

Department of Philosophy

Indiana University-Purdue University, Indianapolis

\section{References}

Appiah, K. Anthony. 2001. "Grounding Human Rights." In Human Rights as Politics and Idolatry, ed. Amy Gutmann, 101-16. Princeton, N.J.: Princeton University Press.

Bagasao, Teresita Marie P. 1998. "Moving Forward through Community Response: Lessons Learned from HIV Prevention in Asia and the Pacific." Health and Human Rights 3(1):8-18.

Benhabib, Seyla. 1995. "Cultural Complexity, Moral Interdependence, and the Global Dialogical Community." In Women, Culture and Development, ed. Martha Nussbaum and Jonathan Glover, 235-55. New York: Oxford University Press.

- 1999. "Sexual Difference and Collective Identities: The New Global Constellation." Signs: Journal of Women in Culture and Society 24(2):335-61. 
British Medical Association. 2001. The Medical Profession and Human Rights: Handbook for a Changing Agenda. New York: Zed.

Chen, Martha. 1995. “A Matter of Survival: Women's Right to Employment in India and Bangladesh." In Women, Culture and Development, ed. Martha Nussbaum and Jonathan Glover, 37-57. New York: Oxford University Press.

Cook, Rebecca. 1999. "Gender, Health and Human Rights." In Health and Human Rights: A Reader, ed. Jonathan M. Mann, Sofia Gruskin, Michael A. Grodin, and George J. Annas, 253-64. London: Routledge.

Council of Europe, Convention on Human Rights and Biomedicine. 1997. Oviedo, April 4.

Dawit, Seble, and Salem Mekuria. 1993. “The West Just Doesn't Get It.” New York Times, December 7, A27.

De Gruchy, Jeanelle, and Laurel Baldwin-Ragavin. 2001. "Serving Nationalist Ideologies: Health Professionals and the Violation of Women's Rights." In Tong 2001, 312-33.

Dickenson, Donna L. 1999. "Cross-Cultural Issues in European Bioethics." Bioethics 13(3):249-55.

Donchin, Anne. 2000. "Autonomy and Interdependence: Quandaries in Genetic Decision Making." In Relational Autonomy: Feminist Perspectives on Autonomy, Agency, and the Social Self, ed. Catriona Mackenzie and Natalie Stoljar, 236-58. New York: Oxford University Press.

Donchin, Anne, and Laura M. Purdy, eds. 1999. Embodying Bioethics: Recent Feminist Advances. Lanham, Md.: Rowman \& Littlefield.

Drèze, Jean, and Amartya Sen. 1989. Hunger and Public Action. Oxford: Clarendon.

Flax, Jane. 2001. "A Constructionist Despite Herself? On Capacities and Their Discontents." In Controversies in Feminism, ed. James P. Sterba, 25-46. Lanham, Md.: Rowman \& Littlefield.

Freedman, Lynn P. 1999. "Reflections on Emerging Frameworks of Health and Human Rights." In Health and Human Rights: A Reader, ed. Jonathan M. Mann, Sofia Gruskin, Michael A. Grodin, and George J. Annas, 227-52. London: Routledge.

Gilligan, Carol. 1982. In a Different Voice: Psychological Theory and Women's Development. Cambridge, Mass.: Harvard University Press.

Holmes, Helen Bequaert. 1999. "Closing the Gaps: An Imperative for Feminist Bioethics." In Donchin and Purdy 1999, 45-63.

Ignatieff, Michael. 2001a. "Human Rights as Idolatry." In Human Rights as Politics and Idolatry, ed. Amy Gutmann, 53-98. Princeton, N.J.: Princeton University Press.

- 2001b. "Human Rights as Politics." In Human Rights as Politics and Idolatry, ed. Amy Gutmann, 3-52. Princeton, N.J.: Princeton University Press.

- 2001c. "Response to Commentators." In Human Rights as Politics and Idolatry, ed. Amy Gutmann, 161-73. Princeton, N.J.: Princeton University Press. 
Ingram, David. 2000. Group Rights: Reconciling Equality and Difference. Lawrence: University of Kansas Press.

Jaggar, Alison. 1983. Feminist Politics and Human Nature. Totowa, N.J.: Rowman \& Allanheld.

- 2003. "Vulnerable Women and Neoliberal Globalization." In Recognition, Responsibility, and Rights: Feminist Ethics and Social Theory, ed. Robin N. Fiore and Hilde Lindemann Nelson, 195-209. Lanham, Md.: Rowman \& Littlefield.

Li, Xiaorong. 1995. "Gender Inequality in China and Cultural Relativism.” In Women, Culture and Development, ed. Martha Nussbaum and Jonathan Glover, 407-25. New York: Oxford University Press.

Lovibond, Sabina. 1989. "Feminism and Postmodernism." New Left Review $178(1): 5-28$.

Luna, Florencia. 2001. "Globalization, Gender and Research.” In Tong 2001, 254-65.

Macklin, Ruth. 1999. Against Relativism: Cultural Diversity and the Search for Ethical Universals in Medicine. New York: Oxford University Press.

Mann, Jonathan, Lawrence Gostin, Sofia Gruskin, Troyen Brennan, Zita Lazzarini, and Harvey Fineberg. 1999. "Health and Human Rights." In Health and Human Rights: A Reader, ed. Jonathan M. Mann, Sofia Gruskin, Michael A. Grodin, and George J. Annas, 7-20. London: Routledge.

Mata, Leonardo. 1988. "A Public Health Approach to the Food-MalnutritionEconomic Recession Complex." In Health, Nutrition and Economic Crisis: Approaches to Public Policy in the Third World, ed. David Bell and Michael Reich. Dover, Mass.: Auburn.

Meyers, Diana Tietjens. 1994. Subjection and Subjectivity: Psychoanalytic Feminism and Moral Psychology. New York: Routledge.

Minow, Martha. 1990. Making All the Difference: Inclusion, Exclusion, and American Law. Ithaca, N.Y.: Cornell University Press.

Munck, Ronaldo, and Denis O'Hearn, eds. 1999. Critical Development Theory: Contributions to a New Paradigm. New York: Zed.

Narayan, Uma. 1997. Dislocating Cultures: Identities, Traditions, and Third World Feminism. New York: Routledge.

Nicholas, Barbara. 1999. "Strategies for Effective Transformation." In Donchin and Purdy 1999, 239-52.

Nnaemeka, Obioma. 1996. "Development, Cultural Forces, and Women's Achievements in Africa." Law and Policy 18(3-4):251-79.

- 1997. The Politics of (M)Othering: Womanhood, Identity, and Resistance in African Literature. New York: Routledge.

Noddings, Nel. 1984. Caring: A Feminist Approach to Ethics and Moral Education. Berkeley: University of California Press.

Nussbaum, Martha. 1992. "Justice for Women!" New York Review of Books, October $8,43-48$.

. 1998. "Public Philosophy and International Feminism." Ethics 108(4): 762-96. 
1999. Sex and Social Justice. New York: Oxford University Press.

2000. Women and Human Development: The Capabilities Approach. Cambridge: Cambridge University Press.

Nzegwu, Nkiru. 1995. "Recovering Igbo Traditions: A Case for Indigenous Women's Organizations in Development." In Women, Culture and Development, ed. Martha Nussbaum and Jonathan Glover, 444-65. New York: Oxford University Press.

Okin, Susan Moller. 1995. "Inequalities between the Sexes in Different Cultural Contexts." In Women, Culture and Development, ed. Martha Nussbaum and Jonathan Glover, 274-97. New York: Oxford University Press.

O'Neill, Onora. 1993. "Justice, Gender, and International Boundaries." In The Quality of Life, ed. Martha Nussbaum and Amartya Sen, 303-23. Oxford: Oxford University Press.

Peel, Michael. 2002. "Peacefully, Nigerian Women Win Changes from Big Oil." Christian Science Monitor, August 12. Available online at http://www.csmonitor. com/2002/0812/p07s02-woaf.htm. Last accessed September 10, 2003.

Rawls, John. 1971. A Theory of Justice. Cambridge, Mass.: Harvard University Press, Belknap Press.

- 1999. The Law of Peoples. Cambridge, Mass.: Harvard University Press.

Robinson, Mary. 2001. "Bridging the Gap between Human Rights and Development: From Normative Principles to Operational Relevance.” World Bank Presidential Fellows' Lecture, December 3. Available online at http://www. worldbank.org/wbi/B-SPAN/sub_mary_robinson.htm. Last accessed September 10, 2003.

Rosenberg, Tina. 2002. "Globalization: The Free-Trade Fix." New York Times Magazine, August 18, 28.

Sakamoto, Hyakudai. 1999. “Towards a New 'Global Bioethic.'” Bioethics 13(3-4): 191-97.

Salles, Arleen L. F. 2002. "Autonomy and Culture: The Case of Latin America." In Bioethics: Latin American Perspectives, ed. Arleen L. F. Salles and Maria Julia Bertomeu, 9-26. New York: Rodophi.

Sen, Amartya. 1985. Commodities and Capabilities. Amsterdam: North-Holland.

- 1990. "Gender and Cooperative Conflicts." In Persistent Inequalities: Women and World Development, ed. Irene Tinker, 123-49. New York: Oxford.

- 2000. "East and West: The Reach of Reason." New York Review of Books, July 20, 33-38.

Sherwin, Susan. 1992. No Longer Patient: Feminist Ethics and Health Care. Philadelphia: Temple University Press.

- 2001. "Foundations, Frameworks, Lenses: The Role of Theories in Bioethics." In Tong 2001, 12-26.

Shinn, Carolynne. 1999. "The Right to the Highest Attainable Standard of Health: Public Health's Opportunity to Reframe a Human Rights Debate in the United States." Health and Human Rights 4(1):114-33.

Sunstein, Cass. 1995. "Gender, Caste and Law." In Women, Culture and Devel- 
opment, ed. Martha Nussbaum and Jonathan Glover, 332-59. New York: Oxford University Press.

- 2001. Designing Democracy: What Constitutions Do. New York: Oxford University Press.

Tong, Rosemarie. 2004. "Feminist Perspectives, Global Bioethics, and the Need for Moral Language Translation Skills." In Feminist Bioethics, Human Rights and the Developing World: Integrating Global and Local Perspectives, ed. Rosemarie Tong, Anne Donchin, and Susan Dodds. Lanham, Md.: Rowman \& Littlefield.

Tong, Rosemarie, ed. 2001. Globalizing Feminist Bioethics: Crosscultural Perspectives. Boulder, Colo.: Westview.

UNESCO. 2000. "Universal Declaration on the Human Genome and Human Rights: From Theory to Practice." New York: UNESCO.

Valdés, Margarita M. 1995. "Inequality in Capabilities between Men and Women in Mexico." In Women, Culture and Development, ed. Martha Nussbaum and Jonathan Glover, 426-32. New York: Oxford University Press.

Walker, Alice. 1993. Possessing the Secret of Joy. New York: Harcourt Brace.

Walker, Margaret Urban. 2003. "Truth and Voice in Women's Rights." In Recognition, Responsibility, and Rights, ed. Robin N. Fiore and Hilde Lindemann Nelson, 169-80. Lanham, Md.: Rowman \& Littlefield.

Warrior Marks. 1993. Directed by Alice Walker and Pratibha Parmar. New York: Women Make Movies.

Williams, Patricia J. 1991. The Alchemy of Race and Rights. Cambridge, Mass.: Harvard University Press.

World Bank. 2001. Engendering Development: Through Gender Equality in Rights, Resources, and Voice. New York: Oxford University Press and World Bank.

World Conference of Bioethics. 2000. "Bioethics Declaration.” Gijón, Spain. Available online at http://www.sibi.org/ingles/declaration.htm.

Young, Iris Marion. 1990. Justice and the Politics of Difference. Princeton, N.J.: Princeton University Press. 